\title{
Glucocorticoids Regulate Gene Expression and Repress Cellular Proliferation in Human Uterine Leiomyoma Cells
}

\author{
Shannon Whirledge • Darlene Dixon · John A. Cidlowski
}

Published online: 7 February 2012

(C) Springer Science+Business Media, LLC (outside the USA) 2012

\begin{abstract}
Sex hormones and growth factors have been implicated in the pathogenesis of uterine leiomyomas. The uterus is also an abundant source of the glucocorticoid receptor but its role and function have been largely ignored. Human samples of uterine leiomyomas and matched myometrium retain expression of the glucocorticoid receptor (GR) suggesting a potential role for GR in leiomyoma function. However, hormone responsive gene expression varies between normal myometrium and leiomyoma cells. We now employ genome-wide microarray studies comparing glucocorticoid and estrogen-treated human uterine leiomyoma cells to those treated with both steroids to identify the potential role of glucocorticoids in uterine leiomyoma cells. Treatment with the synthetic glucocorticoid dexamethasone (Dex) regulated 3,128 probes. Estrogen $\left(\mathrm{E}_{2}\right)$ treatment identified 2,094 probes, and in the presence of both hormones, 4,626 probes were regulated. Of the 552 probes
\end{abstract}

S. Whirledge · J. A. Cidlowski

Laboratory of Signal Transduction, National Institute of

Environmental Health Sciences, National Institutes of Health,

Department of Health and Human Services,

111 TW Alexander Drive,

Research Triangle Park, NC 27709, USA

D. Dixon

Cellular and Molecular Pathology Branch, National Toxicology

Program, National Institute of Environmental Health Sciences,

National Institutes of Health,

Department of Health and Human Services,

111 TW Alexander Drive,

Research Triangle Park, NC 27709, USA

J. A. Cidlowski $(\square)$

NIH/NIEHS,

MD F3-07, P.O. Box 12233, Research Triangle Park,

NC 27709, USA

e-mail: cidlows1@niehs.nih.gov identified, the majority of genes co-regulated by Dex, $\mathrm{E}_{2}$, and Dex $+E_{2}$ exhibited co-downregulation. Interestingly, a small group of 17 genes displayed antagonistic regulation by Dex and $E_{2}$, where all genes in this group, Dex reversed the $E_{2}$ effect with. Ingenuity Pathway Analysis of the data identified cell growth, development, and differentiation as significant glucocorticoid regulated pathways. Flow cytometry confirmed that glucocorticoids regulated cell proliferation and significantly reduced the percentage of S-phase cells either in the presence or absence of estrogen in leiomyomas but not smooth muscle cells. Translation of our results suggest that glucocorticoids may play a significant role in regulating uterine leiomyoma gene expression and cell growth, and thus may have implications for therapeutic development of uterine leiomyoma treatment.

Keywords Uterus · Leiomyoma · Glucocorticoid receptor · Estrogen

\section{Introduction}

Uterine leiomyomas (fibroids, myomas), benign tumors originating as overgrowth of smooth muscle and connective tissue of the uterus, are the most frequently occurring tumor of the female reproductive tract, where the lifetime risk in a woman over the age of 45 is more than $60 \%$ [1-3]. Although leiomyomas rarely progress to malignancy, they are the leading cause of hysterectomies in the USA and are associated with pain and infertility [4]. In the search for alternative treatments for leiomyomas, studies have focused on their hormone-responsive characteristics [5, 6]. Dependence on the steroid hormones estrogen and progesterone is well established; however, the etiology of leiomyomas and 
factors that regulate their growth and clinical severity remain poorly understood.

Morphologically similar to the myometrium from which they arise, leiomyomas differ primarily by their aberrant growth. This growth is primarily regulated by steroid hormones. Clinical evidence supports the involvement of estrogen in the growth and development of uterine leiomyomas where growth tends to occur in premenopausal women but regress following withdrawal of estrogen during menopause [7]. Furthermore, prescribing hormone replacement therapy, usually in the form of estrogen, to relieve symptoms of menopause in women is associated with an increase risk of for the development of leiomyomas [8]. Estrogen receptor levels are increased and estrogen metabolism decreased in human uterine leiomyoma compared to normal myometrium $[9,10]$. However, competitive inhibition of estrogen action by treatment with the anti-estrogens tamoxifen and raloxifene only led the inhibition of half the leiomyoma incidence in the Eker rat model, which suggests the involvement of other factors in the growth and development of these tumors [11].

A variety of cellular processes have been ascribed to glucocorticoids, including metabolism, immunosuppressive and anti-inflammatory effects, and actions along the hypothalamic-pituitary-gonadal axis (reviewed in $[12,13]$ ). Glucocorticoids modulate these processes through binding the glucocorticoid receptor (GR), a member of the nuclear steroid receptor super family that functions as a liganddependent transcription factor, to regulate the expression of glucocorticoid-responsive genes (reviewed by [14]). Endogenous glucocorticoids are synthesized in the adrenal cortex under the control of the hypothalamic-pituitaryadrenal axis but their activity can be regulated locally in reproductive tissue through the oxidative activity of $11 \beta$ hydroxysteroid dehydrogenase (11 $\beta$-HSD), an enzyme that catalyzes both oxidative and reductive reactions of glucocorticoids $[15,16]$. Ubiquitous expression of glucocorticoid receptors and presence of local regulatory enzymes supports a role for glucocorticoids in the uterus. Many of the effects induced by glucocorticoids in the uterus are antagonistic to estrogen [17-19]. While estrogens induce growth and differentiation in the uterus, glucocorticoids antagonize estrogen-induced growth and differentiation. Uterine estrogen responses also include water imbibition, vasodilation, and increased uterine weight, which can be blocked by co-administration of glucocorticoids [20]. Microarray analysis of the whole rat uterus identified many genes regulated by estrogen and glucocorticoids [18]. However, previous studies have focused primarily on the antagonistic relationship of glucocorticoids and estrogen in the uterus as a complex multi-cellular organ. The potential for cell-specific effects in the myometrium that may be involved in the growth and development of leiomyomas has not been evaluated.
The focus of current research is to identify the intracellular growth directives of leiomyoma cells. Given that glucocorticoids can antagonize many of the biological effects of estrogens in the uterus, we hypothesized that glucocorticoids might also block estrogen-regulated gene expression or biological functions important for leiomyoma growth. The immortalized human uterine leiomyoma cell line used in these studies represents a system superior to primary cells, which senesce early, to study the molecular characteristics of leiomyomas [21]. These cells retain a phenotypic likeness to human-derived leiomyoma cells, which suggests results found could translate to in vivo discoveries. Therefore, we examined the effects of estrogen and dexamethasone on the global patterns of gene expression using microarray analysis and a significant number of probes were regulated by Dex, $E_{2}$, or a combination thereof. Interestingly, while a majority of the genes identified were regulated in a similar manner by Dex and $E_{2}$, several genes were identified as differentially expressed and a subset was classified as antagonistically regulated. Ingenuity Pathway Analysis identified cellular growth as the function for genes most commonly regulated by dexamethasone. Cell cycle analysis determined that dexamethasone promoted downregulation of cell replication and could antagonize estrogen's effect on cell cycle. These observations highlight the ability of steroid hormones not classically thought of as involved in reproductive function to regulate development and growth of uterine leiomyomas.

\section{Materials and Methods}

\section{Immunohistochemistry}

Tissue samples were immersed in $10 \%$ neutral buffered formalin, fixed overnight, and then placed in $70 \%$ ethanol until time of processing (within $24 \mathrm{~h}$ ). Tissues were paraffinembedded, sectioned at $5 \mu \mathrm{m}$, and mounted onto Superfrost Plus glass slides (Thermo Scientific, Portsmouth, NH, USA). Glass slides, each containing a section of the normal uterus (myometrium) or leiomyoma, were stored at room temperature in dust-free slide boxes until the time of immunohistochemical staining. Formalin-fixed, paraffinembedded mouse tissue on slides was deparaffinized, rehydrated, and endogenous peroxide blocked with 3\% hydrogen peroxide. Antigen retrieval was performed with heat and pressure, immersed in Citrate Buffer (Biocare Medical, CA, USA). Protein blocking was performed with $10 \%$ Normal Donkey Serum (Jackson Immunoresearch Laboratories, Inc., West Grove, PA) for $20 \mathrm{~min}$, followed by the Avidin-Biotin Blocking Kit (Vector Laboratories, Burlingame, CA, USA). Primary antibody, GR and Normal Rabbit Serum (Jackson Immunoresearch Laboratories, Inc., West Grove, PA, USA), 
was incubated overnight at $4 \mathrm{C}$ at a 1:300 dilution. Secondary antibody of Donkey anti-Rabbit (Jackson Immunoresearch Laboratories, Inc., West Grove, PA, USA) was incubated for 30 min at 1:500 dilution. Label incubation was Vector RTU (Vector Laboratories, Burlingame, CA, USA) for $30 \mathrm{~min}$ also. Slides were developed with DAB, counterstained with Hematoxylin, dehydrated, cleared, and coverslipped. Sections were scanned at $\times 40$ using an Aperio Scanscope XT Scanner (Aperio Technologies, Inc., Vista, CA, USA).

Culture of Human Uterine Leiomyoma and Uterine Smooth Muscle Cells

Immortalized human uterine leiomyoma cells (UtLM) and uterine smooth muscle cells (UtSMC) were obtained from our colleague Dr. Darlene Dixon and grown in a standard tissue culture incubator at $37^{\circ} \mathrm{C}$, with $95 \%$ humidity and $5 \%$ carbon dioxide [21]. UtLM cells were cultured in Minimum Essential Medium (MEM; Sigma, St. Louis, MO, USA) supplemented with $19 \%$ fetal bovine serum (FBS; Atlanta Biologicals, Lawrenceville, GA, USA), vitamins (Invitrogen (Gibco), Carlsbad, CA, USA), essential and nonessential amino acids (Invitrogen (Gibco)), and L-glutamine (Invitrogen (Gibco)). UtSMC cells were cultured in media containing supplements and fetal bovine serum from a SmGM-2 Bullet Kit (Lonza, Walkersville, MD, USA). Twenty-four hours prior to treatment, media were changed to phenol red-free MEM (UtLM) or phenol-red free DMEM (UtSMC) with charcoal dextran-treated (stripped) FBS (Hyclone, Logan, UT, USA). An immortalized uterine human endometrial cancer cell line (ECC1) was obtained from the American Type Culture Collection (Manassas, VA, USA) and grown in a standard tissue culture incubator at $37^{\circ} \mathrm{C}$, with $95 \%$ humidity and $5 \%$ carbon dioxide. ECC1 cells were maintained in RPMI Medium 1640 (Invirtogen (Gibco), Carlsbad, CA, USA) supplemented with 5\% FBS and $24 \mathrm{~h}$ prior to treatment, media were changed to phenol red-free RPMI 1640 containing 5\% charcoal dextran-treated (stripped) FBS. Cells were treated with $100 \mathrm{nM}$ Dexamethasone (Dex; 1,4-pregnadien-9-fluoro-16-methyl-11 $\beta, 17,21$ triol-3,20-dione) or $10 \mathrm{nM}$ Estrogen $\left(\mathrm{E}_{2} ; 1,3,5(10)\right.$ Estratrien-3,17 $\beta$-Diol) purchased from Steraloids (Newport, RI, USA).

\section{Western Blotting Analysis}

Treated cells grown in $9 \mathrm{~cm}$ dishes were washed twice with ice-cold PBS, treated with $350 \mu 1$ radioimmunoprecipitation buffer with the addition of protease inhibitor cocktail tablets (Roche, Indianapolis, IN, USA) and phosphatase inhibitor cocktail set II (Calbiochem, La Jolla, CA, USA), scraped off the plate, and incubated at $4^{\circ} \mathrm{C}$ for $30 \mathrm{~min}$. Cellular debris was removed by centrifugation at 13,200 rpm for $20 \mathrm{~min}$ at $4^{\circ} \mathrm{C}$ and suppernant collected. Protein concentration was determined using a BCA protein quantitation kit (Pierce, Rockford, IL, USA). Samples containing $40 \mu \mathrm{g}$ of protein were fractionated on a $4-20 \%$ ReadyGel Tris-Gly gels (Bio-Rad, Hercules, CA, USA) and separated proteins were then transferred onto a nitrocellulose membrane. Membranes were blocked for $1 \mathrm{~h}$ with $10 \%$ skim milk in TBST (Trisbuffered saline with $0.1 \%$ Tween 20 ) and subsequently probed with anti-GR antibodies (1:1,000; [22]), anti-ER antibodies (1:750; Immunotech, Marseille, France), or anti- $\beta$-actin antibodies (1:10,000; Millipore, Temecula, CA, USA). Immunoreactivity was visualized by incubation with horseradish peroxidase-linked secondary antibodies (GE Healthcare, Buckinghamshire, UK) and treatment with enhanced chemiluminescence reagents.

\section{RNA Isolation}

Total RNA was extracted from UtLM cells using the QIAGEN RNeasy mini kit (Qiagen, Valencia, CA, USA) according to the manufacturer's protocol. Deoxyribonuclease (DNase) treatment was performed on-column using a ribonucleasefree DNase Kit (Qiagen) according to the manufacturer's instruction. Samples were quantified by Nanodrop ND1000 (Thermo Scientific, Wilmington, DE, USA) spectrophotometer and purity was analyzed by the 260:280 absorbance ratio.

\section{Quantitative Real-Time PCR}

Quantitative real-time reverse transcription-PCR (RT-PCR) was performed by using the $7900 \mathrm{HT}$ sequence detection system and predesigned primer/probe sets from Applied Biosystems (Foster City, CA, USA) according to the manufacturer's instructions. RT-PCRs were performed on $100 \mathrm{ng}$ total RNA using the One-Step RT-PCR Universal Master Mix reagent. Standard curves were generated by serial dilution of a preparation of total RNA isolated from UtLM cells. The signal obtained from each gene primerprobe set was normalized to that of the unregulated housekeeping gene peptidylprolyl isomerase B (cyclophilin B) primer-probe set (Applied Biosystems). Each primer-probe set was analyzed with at least three independent biological replicates.

\section{Microarray Analysis}

Microarrays were completed of three biologically independent replicates for each group (Vehicle, Dex, $E_{2}$, and Dex $+E_{2}$ ) for a total of 12 microarrays. Each microarray was hybridized using a pooled RNA sample, and each pool was created from equal amounts of total RNA from three independent RNA samples, representing individual plates. Gene expression analysis was 
conducted using Agilent Whole Genome Whole Human 4× 44 multiplex format oligonucleotide arrays (catalog no. 014850; Agilent Technologies, Santa Clara, CA, USA) following the Agilent 1-color microarray-based gene expression analysis protocol. Starting with an aliquot of $500 \mathrm{ng}$ of total RNA from each pool, Cy3-labeled cRNA was produced using the manufacturer's protocol. For each sample, $1.65 \mu \mathrm{g}$ of Cy3labeled cRNAs were fragmented and hybridized for $17 \mathrm{~h}$ in a rotating hybridization oven. Slides were washed and then scanned with an Agilent Scanner. Data were obtained using the Agilent Feature Extraction software (v9.5), using the 1color defaults for all parameters. The Agilent Feature Extraction Software performed error modeling, adjusting for additive and multiplicative noise. The resulting data were processed using the Rosetta Resolver ${ }^{\circledR}$ system (version 7.2; Rosetta Biosoftware, Kirkland, WA, USA). Principal Component Analysis (PCA) was performed on all samples and all probes to reduce the dimensionality of the data while preserving the variation in the data set. This allowed us to then assess the similarities and differences of samples within a treatment group and between treatment groups. Errorweighted ratios that Resolver generates and the associated $p$ value were used to identify differentially expressed probes. The ratios used to determine these lists were: $\mathrm{E}_{2}$-treated cells/ Vehicle-treated cells, Dex-treated cells/Vehicle-treated cells, $\mathrm{Dex}+\mathrm{E}_{2}$-treated cells/Vehicle-treated cells, Dex-treated cells/ Estrogen-treated cells, Dex $+\mathrm{E}_{2}$-treated cells $/ \mathrm{E}_{2}$-treated cells, and Dex $+E_{2}$-treated cells/Dex-treated cells. The lists of probe sets generated in Rosetta Resolver that were responsive to Dex, $E_{2}$, or Dex $+E_{2}$ were analyzed in the Ingenuity Pathway Analysis tool (version 6.5; Ingenuity Systems, Redwood City, CA, USA). The average expression value of duplicate identifiers for the same molecule was used in the analyses to eliminate redundancy. Functional pathway analysis identified pathways from the Ingenuity Pathways Analysis library of functional pathways and ranked them by ratio (number of

\section{Glucocorticoid Receptor}

\section{Myometrium}

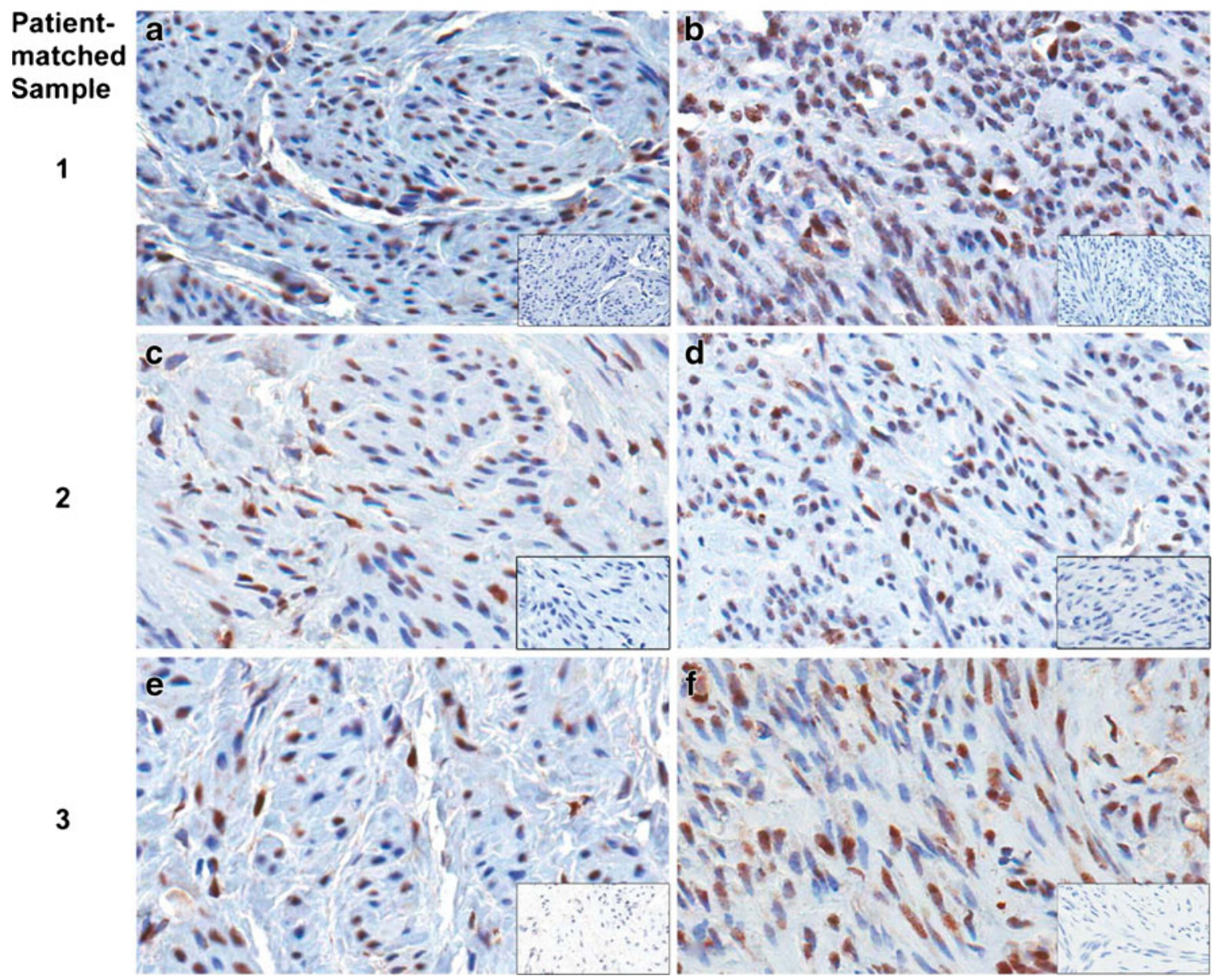

Fig. 1 GR staining of human matched normal myometrium and leiomyoma patient samples 1-3. Inset represents negative control for each tissue sample. The magnification for all panels is $\times 40$ 
genes from the data set that map to the pathway divided by the total number of genes that map to the functional pathway). The highest ranked pathway that met $P$ value $<0.05$ (Fischer's exact test) is displayed.

Flow Cytometric Analysis

Flow cytometry was employed to assess cell proliferation and DNA content. UtLM cells were treated with Vehicle (water), $100 \mathrm{nM}$ Dex, $10 \mathrm{nM} \mathrm{E}$, or $100 \mathrm{nM} \mathrm{Dex}+10 \mathrm{nM} \mathrm{E}_{2}$ for 24,48 , and $72 \mathrm{~h}$. After treatment, cells were collected by trypsin digestion, fixed by the slow addition of cold $70 \%$ ethanol to a volume of approximately $2-3 \mathrm{ml}$ with agitation, and stored at $-20^{\circ} \mathrm{C}$ overnight. Fixed cells were pelleted from the ethanol, washed twice in $3 \mathrm{ml}$ of $1 \times \mathrm{PBS}$, and stained in $1 \mathrm{ml}$ of $20 \mathrm{ug} / \mathrm{ml}$ propidium iodide, 1,000 units RNaseOne (Promega) in $1 \times$ PBS. Cells were excited using a 488-nm argon laser and emission was detected at $585 \mathrm{~nm}$. Analysis was carried out using a Becton Dickinson FACSort flow cytometer (Franklin Lakes, NJ, USA) and CELLQuest software (Becton Dickinson Immunocytometry Systems, San Jose, CA, USA). Individual cells (10,000 per experimental sample) were selected by gating on a propidium idodide versus width dot plot to exclude cell aggregates and debris.

\section{Cell Proliferation}

For cell proliferation assays, UtLM cells were plated at a density of $6.4 \times 10^{4}$ cells per well in $10 \mathrm{~cm}$ culturing plates. Twenty-four hours prior to treatment, media were changed to phenol red-free MEM with charcoal dextran-treated (stripped) FBS. Cells were treated with 100 nM Dexamethasone, $10 \mathrm{nM}$ Estrogen, or $100 \mathrm{nM}$ Dexamethasone and $10 \mathrm{nM}$ Estrogen $24 \mathrm{~h}$ after addition of phenol-red free/ stripped media. Cells trypsinized from plates were counted at time 0, 24, 48, and $72 \mathrm{~h}$ with Countess Automated Cell Counter (Invitrogen) using chamber slides with a 1:1 dilution of cells to Trypan blue stain $0.4 \%$ (Invitrogen). Each sample was counted in duplicate.

\section{Statistical Analysis}

Data are presented as means \pm SEM. Statistical significance was determined by ANOVA with Tukey's post-hoc analysis.

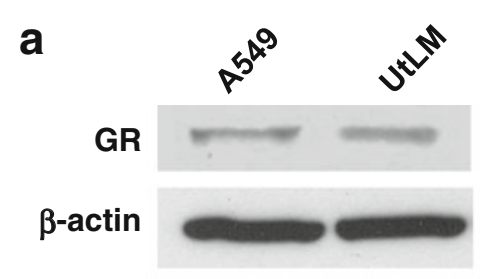

\section{b}
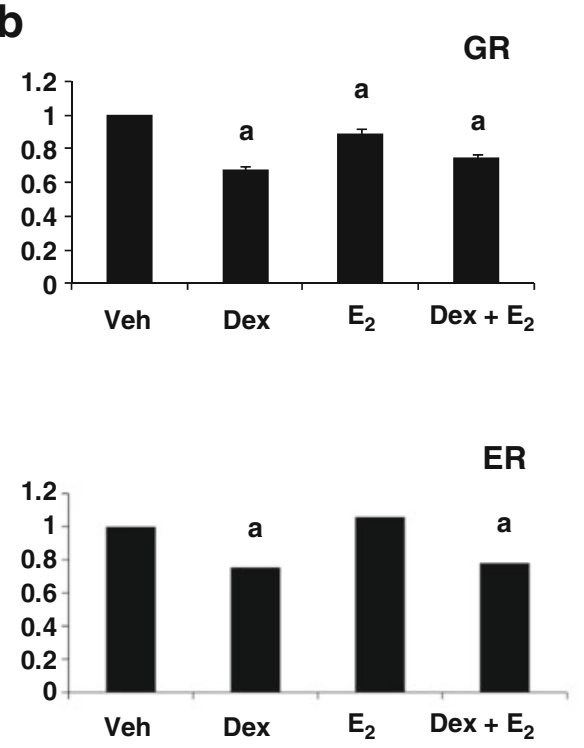

Fig. 2 a Western blot of GR in A549 v. UtLM and ER in MCF7 v. UtLM cells untreated. b Quantitative RT-PCR of RNA harvested from UtLM cells treated for $6 \mathrm{~h}$ with $100 \mathrm{nM}$ of Dex, $10 \mathrm{nM}$ of $\mathrm{E}_{2}$, or $100 \mathrm{nM}$ Dex and $10 \mathrm{nM} \mathrm{E}_{2}$. c Western blot for GR, ER, and $\beta$-actin
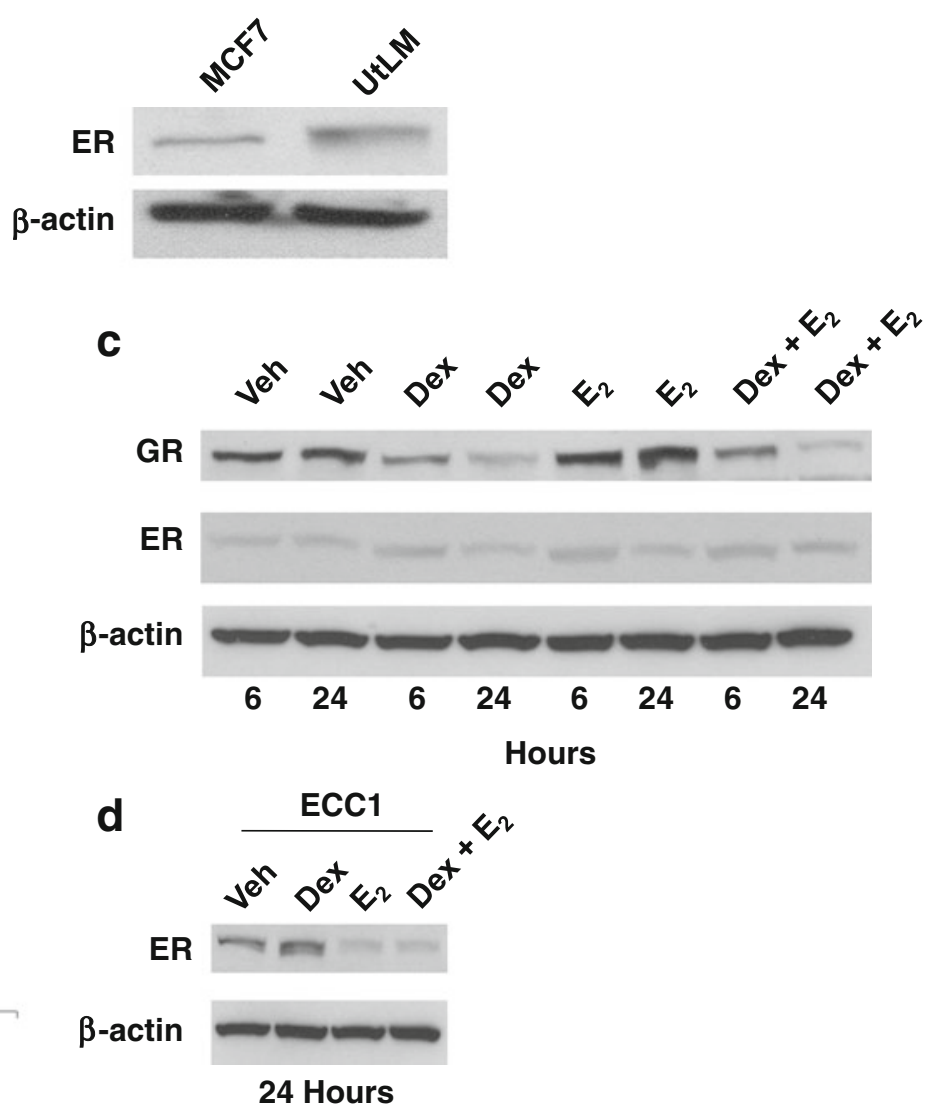

using protein extracts from UtLM cells treated for 6 and $24 \mathrm{~h}$ with Veh, Dex, $\mathrm{E}_{2}$, or $\mathrm{D}+\mathrm{E}$. Values represent mean $\pm \mathrm{SEM}$. Letters represent groups with means statistically different as determined by ANOVA 


\section{Results}

Glucocorticoid Receptor Expressed in Normal Myometrium and Leiomyoma from Human Patient

To determine if the glucocorticoid receptor (GR) is present in human tissue from normal myometrium and leiomyoma, hGR staining was examined in three patient's samples from matched myometrium and a leiomyoma tumor. Nuclei stained positive in both myometrial and leiomyoma samples to similar levels (Fig. 1), which reveals that hGR expression is present in both normal and tumor tissue. These data suggests that the glucocorticoid receptor may function to regulate the biology of both normal and leiomyoma myometrium. In order to dissect the function of the receptor in leiomyomas, an immortalized human cell line was utilized for subsequent studies.

Expression of Glucocorticoid Receptor (GR) and Estrogen Receptor (ER) in UtLM Cells

To evaluate the potential presence of hGR and confirm the expression of ER in human uterine leiomyomas, western blotting analysis compared expression of GR in UtLM cells to A549 cells, a human lung adenocarcinoma cell line with endogenous hGR expression, and ER expression in MCF-7 cells with that in UtLM [23]. Levels of hGR in UtLM cells were comparable to those found in lung A549 cells, as were levels of ER in UtLM cells compared to breast cancerMCF7 cells (Fig. 2a). Quantitative RT-PCR and western blots were used to determine whether hormone treatments would alter expression of hGR or ER in UtLM cells. After $6 \mathrm{~h}$ treatment with Dex, $\mathrm{E}_{2}$, or Dex $+\mathrm{E}_{2}$, hGR expression was statistically lower in Dex, $E_{2}$, and Dex $+E_{2}$ treatment (Fig. 2b). Dex treatment significantly reduced ER mRNA expression levels and co-treatment with $\mathrm{E}_{2}$ did not antagonize this effect. Levels of $\mathrm{ER}$ with $\mathrm{E}_{2}$ treatment alone were not significantly different from Vehicle-treated cells at $6 \mathrm{~h}$.

Glucocorticoid receptor protein expression was analyzed by Western blot to confirm patterns of expression evident with hormone treatment by quantitative RT-PCR (Fig. 2c). Levels of hGR expression with Dex, $E_{2}$, and Dex $+E_{2}$ treatment were comparable to levels of RNA found at $6 \mathrm{~h}$. Trends of declining hGR expression with Dex and Dex $+\mathrm{E}_{2}$ treatment were evident at $6 \mathrm{~h}$ and were further exaggerated by $24 \mathrm{~h}$. ER was also examined by Western blot for hormone regulation at 6 and $24 \mathrm{~h}$. Treatment with Dex, $\mathrm{E}_{2}$, and Dex $+\mathrm{E}_{2}$ all appear to have an effect on protein expression at $24 \mathrm{~h}$ but little to no change evident at $6 \mathrm{~h}$, which likely reflects the known half-life of the proteins. Estrogen is known to mediate downregulation its receptor, which is true for ECC1 cells, an immortalized human uterine epithelial cell line, but not UtLM cells (Fig. 2d) [24]
Fig. 3 Selective expression of glucocorticoid and estrogen regulated genes in a human uterine leiomyoma cell line. a Probe sets regulated by Dexamethasone (Dex, Dex vs. Vehicle; left-hand circle) are compared with probe sets regulated by Estrogen $\left(\mathrm{E}_{2}\right)$ in female $\left(\mathrm{E}_{2}\right.$ vs. Vehicle; right-hand circle) and probe sets regulated by Dex and $\mathrm{E}_{2}($ Dex $+\mathrm{E}($ Dex $+\mathrm{E} 2$ vs. Vehicle). The overlapping circles represent probe sets that are common between treatment types. b The number of genes induced (white) or repressed (gray) in each treatment are represented in the figure. From left to right, the first bar represents Dex responsive probe sets, the second bar represents probe sets responsive to $\mathrm{E}_{2}$, and the third bar represents probe sets responsive to Dex $+\mathrm{E}_{2}$
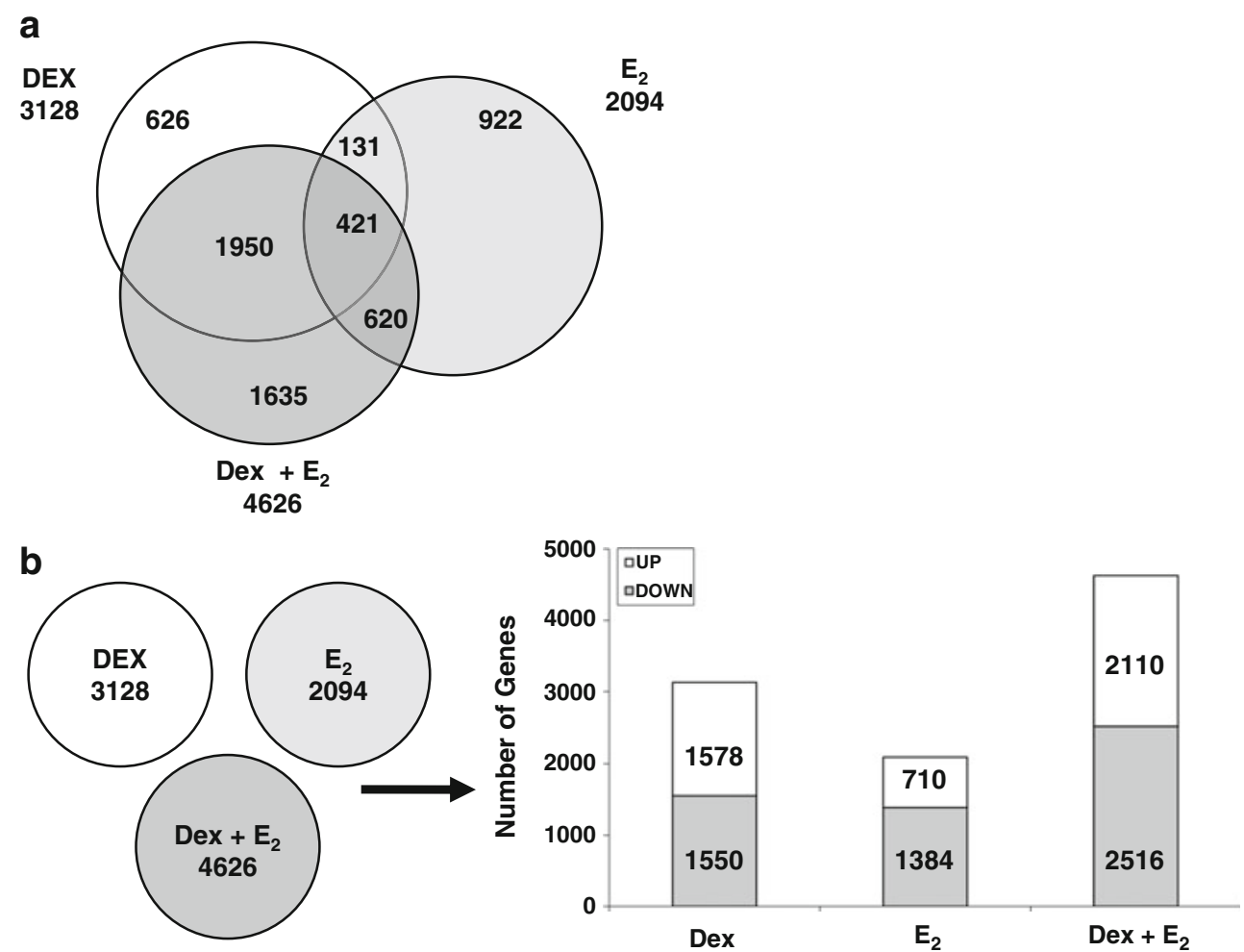
Dexamethasone- and Estrogen-Induced Changes in Gene Expression in UtLM Cells

Despite the clear effects of Dex and $\mathrm{E}_{2}$ on the biological functions within the whole uterus, it is poorly understood what the actions are in an abnormal uterine cell type, such as the leiomyoma [18]. Therefore, we evaluated whether Dex or $\mathrm{E}_{2}$ treatment could induce changes in gene expression in UtLM cells following a 6-h treatment. Comparison of significantly regulated hybridized probes (treatment/Vehicle, $P<0.001)$ revealed 9,848 probes identifying genes regulated by Dex, $E_{2}$, or Dex $+E_{2}$. Of these, 3,128 were regulated by Dex alone, 2,094 were regulated by $\mathrm{E}_{2}$ alone, and 4,626 were regulated in the presence of both Dex and $\mathrm{E}_{2}$ (Fig. 3a). Interestingly, there was significant overlap between those probes regulated only in the presence of Dex and those regulated by Dex plus $E_{2}$ (1,950 probes identified). There were 421 probes that were commonly regulated by Dex, $E_{2}$, and Dex $+E_{2}$. A unique set of 1,635 probes exist for genes regulated only in the presence of both hormones. The direction of regulation was compared between the three treatment types. About half of the Dex and half of the Dex $+E_{2}$-regulated probes were changed by treatment in the same direction (abundance of upregulated and downregulated probes; Fig. 3b). However, in $\mathrm{E}_{2}$-treated cells, the direction of regulation favored repression of gene expression. We confirmed several of the Dex- and $E_{2}$-specific gene expression profiles by quantitative real-time polymerase chain reaction (qRT-PCR) analysis (Fig. 4). The genes ERBB receptor feedback inhibitor 1 (ERRFI1) and claudin 14 (CLDN14) confirmed the pattern of expression for genes
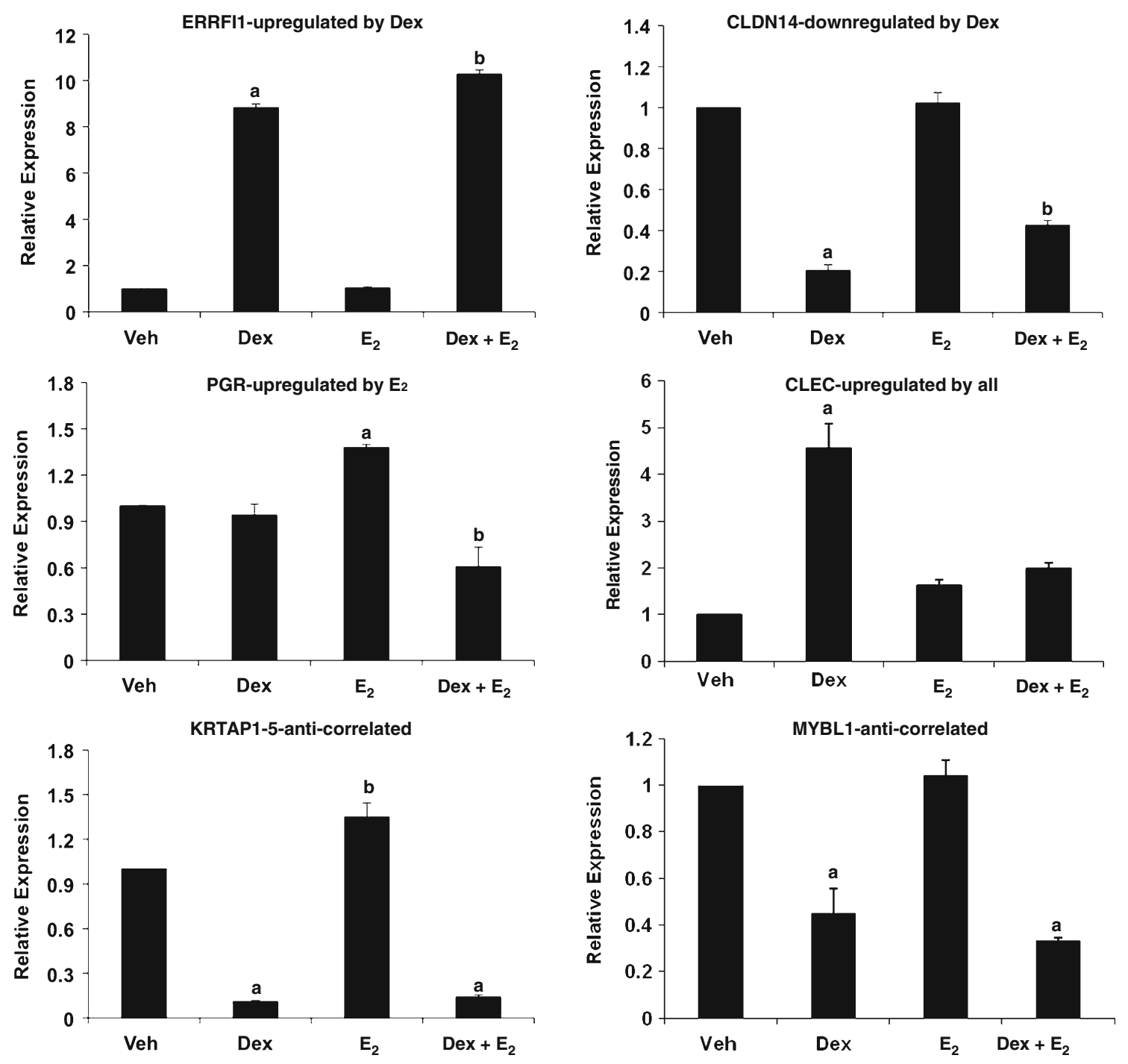

Fig. 4 Microarray results of representative glucocorticoid and estrogen regulated genes were confirmed by qRT-PCR. Letters represent groups with statistically different means. Values represent mean \pm SEM.

All genes analyzed are statistically significant at $p<0.01$ except PGR and CCL15 which are significant at $p<0.05$ 

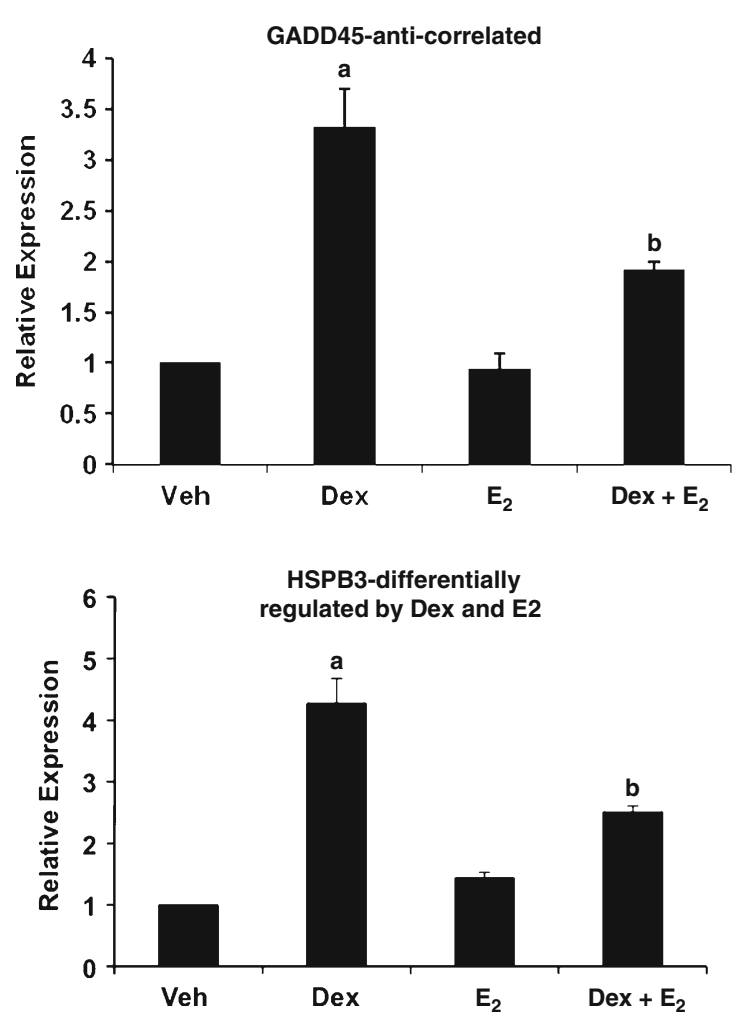

Fig. 4 (continued)

that are Dex responsive, up- and downregulated respectively, and progesterone receptor $(P G R)$ confirms the pattern of expression for $\mathrm{E}_{2}$ responsive genes. Confirmation of C-type lection domain contain protein (CLEC) upregulation under all treatment conditions represents 1 of the 421 probes that is commonly regulated by Dex, $E_{2}$, and Dex $+E_{2}$. The genes keratin associated protein 1-5 (KRTAP1-5), v-myb avian myeloblastosis viral oncogene homolog-like 1 (MYBL1), growth arrest and DNA-damage inducible 45 (GADD45), chemokine (C-C) motif ligand 15 (CCL15), and heat shock protein 3 (HSPB3) confirm the differential regulation of genes by Dex and $\mathrm{E}_{2}$, with KRTAP1-5, MYBL1, and GADD45 showing antagonism by Dex and $E_{2}$. The response to glucocorticoids and their interplay with estrogen in uterine leiomyomas has not been previously described and demonstrates that glucocorticoids may regulate a specific set of genes in these reproductive tumor cells.

\section{Glucocorticoids Inhibit the Estrogen Response} in Anti-Correlated Genes

The regulation of 3,128 probes by Dex in an immortalized uterine leiomyoma cell line prompted us to consider whether genes regulated by Dex were also regulated by $E_{2}$. Probes identified as regulated by Dex, $E_{2}$, and Dex $+E_{2}$ were analyzed for co-regulation. There were 552 probes identified as co-regulated by Dex and $\mathrm{E}_{2}$ (Fig. 5a). Of those identified,

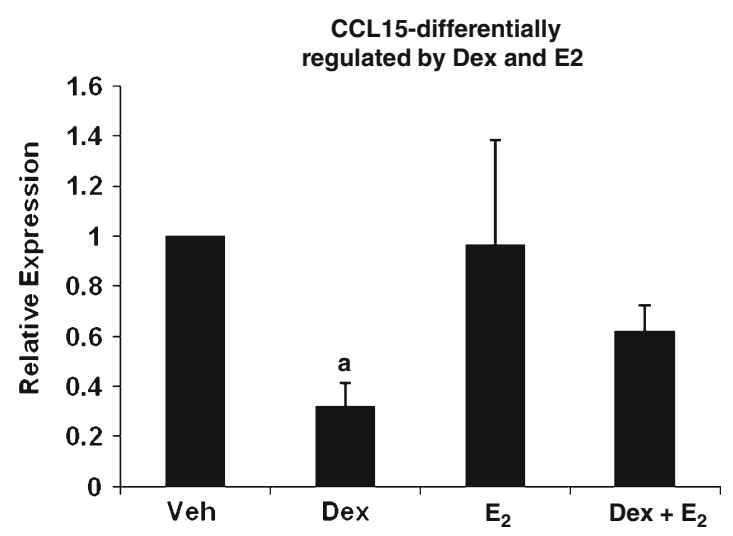

145 were induced and 390 were repressed by all treatments. In addition, 17 probes were found to be anti-correlated (3.1\% of co-regulated probes), where 3 demonstrated the pattern of Dex induction and $\mathrm{E}_{2}$ repression and 14 were induced by $\mathrm{E}_{2}$ and repressed by Dex treatment.

To determine the effect on genes co-regulated in the presence of both hormones, we specifically examined the 421 probes regulated under all 3 treatment conditions (Fig. 5b). The majority of those identified (97.1\%) were regulated in the same manner (either induction or repression in all three treatments). However, 12 probes $(2.9 \%$ of coregulated probes) revealed anti-correlated expression patterns and in all identified, treatment with Dex reversed the $E_{2}$ effect cells treated with both hormones. From the 12 identified anti-correlated probes (listed in Table 1), 3 of the probes were upregulated by Dex and Dex $+E_{2}$ but downregulated by $\mathrm{E}_{2}$. The other 9 probes were downregulated by Dex and Dex $+E_{2}$ but upregulated by $E_{2}$. From the anticorrelated genes, KRTAP1-5 was validated by quantitative RT-PCR.

Divergent Gene Expression with Glucocorticoid Treatment in Smooth Muscle and Leiomyoma Cells

To determine if normal uterine smooth muscle cells and uterine leiomyoma cells respond to hormone in a similar manner, expression of GR, the estrogen receptor (ER), and 
A

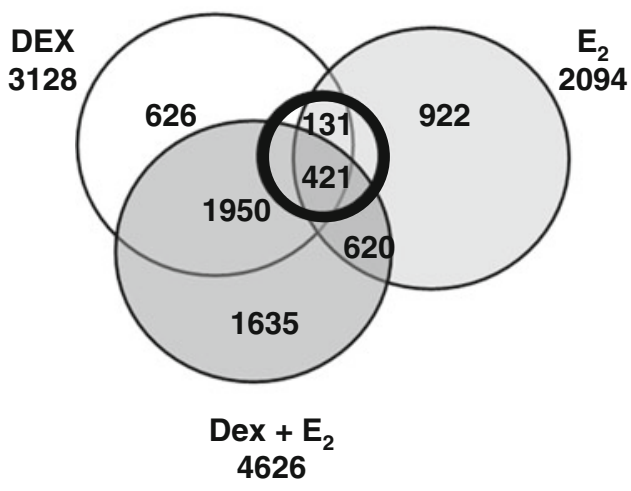

B

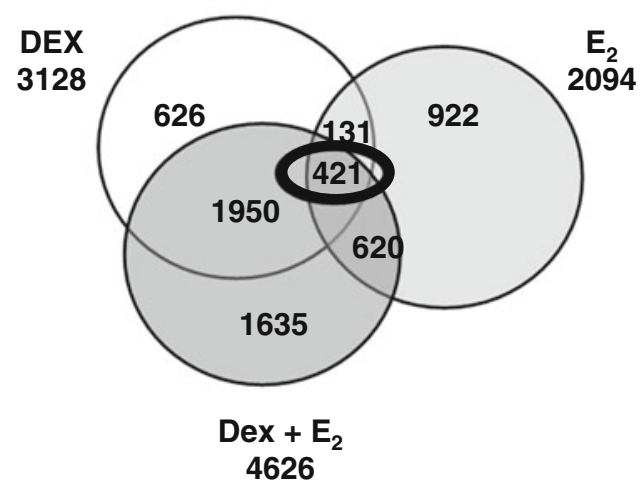

Fig. 5 Comparison of genes commonly regulated by Dexamethasone (Dex) and Estrogen $\left(E_{2}\right)$. a Genes common to Dex, $E_{2}$, and Dex $+E_{2}$ are graphed based on direction of regulation. Genes are divided into the following categories: upregulated by all treatments, down-regulated by all treatments, anti-correlated: upregulated by Dex/downregulated by $E_{2}$, and anti-correlated: upregulated by $E_{2} /$ downregulated by Dex. b Genes regulation overlapping in all three treatment groups (Dex, $\mathrm{E}_{2}$,

glucocorticoid-responsive genes (serine/threonine-protein kinase $(S G K)$ and FK506 binding protein 5 (FKBP5)) were examined following glucocorticoid and estrogen treatment
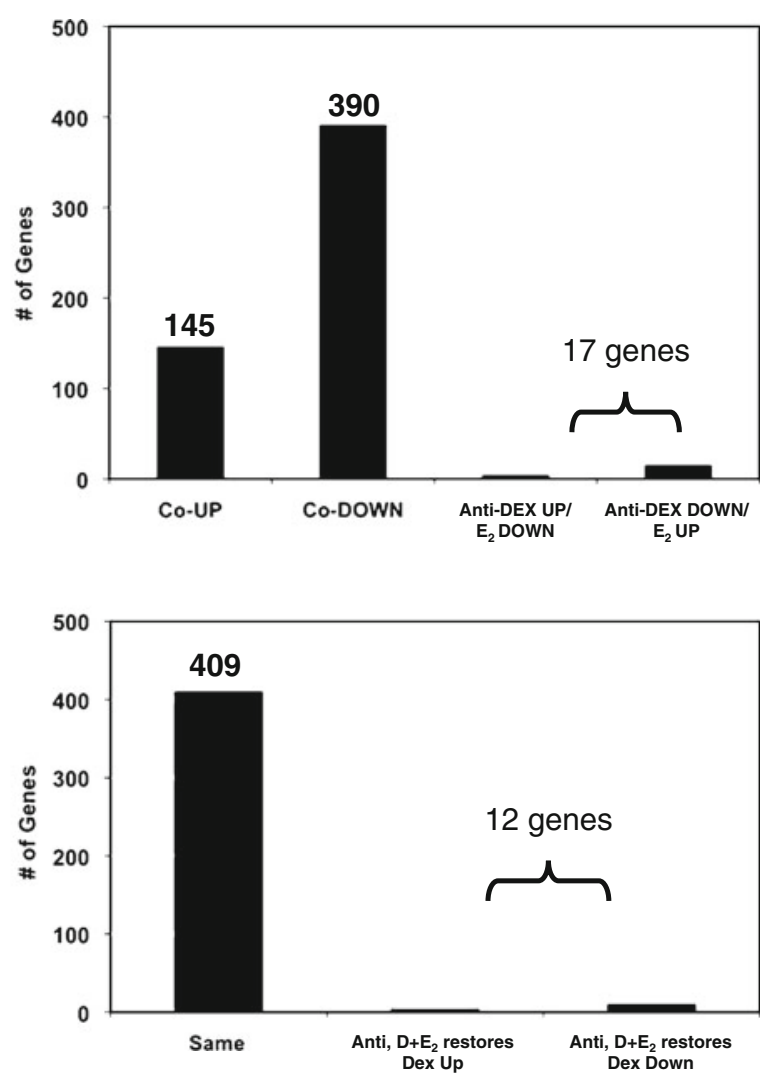

and Dex $+E_{2}$ ) were clustered according to direction of regulation and graphed by the following categories: same direction of regulation, anticorrelated Dex and Dex $+\mathrm{E}_{2}$ upregulated/ $\mathrm{E}_{2}$ downregulated, and anticorrelated Dex and Dex $+E_{2}$ downregulated/E $E_{2}$ upregulated. Microarray results of representative glucocorticoid and estrogen regulated genes were confirmed by qRT-PCR

by quantitative RT-PCR (Fig. 6). The pattern of gene expression for both GR and ER was not statistically different between the two cell lines. However, glucocorticoid-induced
Table 1 Anti-correlated genes regulated by Dex, $E_{2}$, and Dex $+\mathrm{E}_{2}$

\begin{tabular}{llrrr}
\hline & & Dex & $\mathrm{E}_{2}$ & \multicolumn{1}{c}{$\mathrm{D}+\mathrm{E}_{2}$} \\
\hline KRTAP1-5 & Keratin-associated protein 1-5 & -2.55275 & 1.40666 & -2.27743 \\
FAM46C & Family with sequence similarity 46, member C & -2.47353 & 1.45499 & -2.3209 \\
CREB5 cAMP & Responsive element binding protein 5 & -2.00765 & 1.50704 & -2.08233 \\
C8orf46 & Chromosome 8 open reading frame 46 & -2.39669 & 1.25437 & -2.10952 \\
MYBL1 & v-myb myeloblastosis viral oncogene & -2.15699 & 1.26389 & -2.11973 \\
& homolog (avian)-like 1 & & & \\
DIO2 & Deiodinase, iodothyronine, type II & -1.73141 & 1.51388 & -1.65713 \\
RND3 & Rho family GTPase 3 & -1.66382 & 1.20586 & -1.50033 \\
CISH & Cytokine inducible SH2-containing protein & -1.81448 & 1.18734 & -1.45696 \\
THC1870278 & Unknown & -4.07035 & 2.29788 & -4.34019 \\
GADD45B & Growth arrest and DNA-damage-inducible, beta & 1.66877 & -1.27122 & 1.53253 \\
FGF18 & Fibroblast growth factor 18 & 1.49189 & -1.21526 & 1.7022 \\
AFAP1L1 & Actin filament associated protein 1-like 1 & 1.37607 & -1.21431 & 1.37124 \\
\hline
\end{tabular}



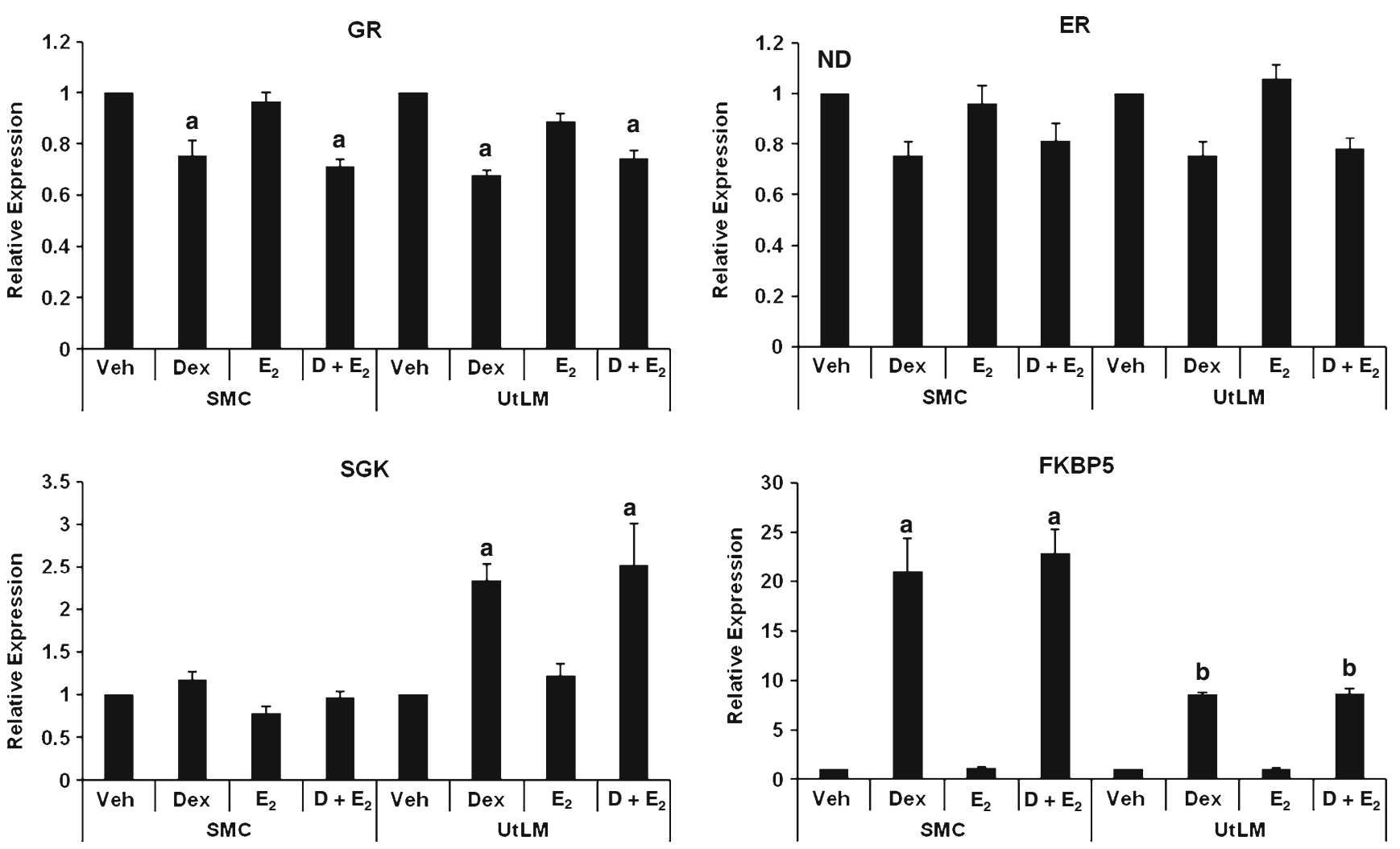

Fig. 6 Gene expression analysis in UtLM and UtSMC cells. Following treatment with $100 \mathrm{nM}$ Dex, $10 \mathrm{nM}$ of $\mathrm{E}_{2}$, or $100 \mathrm{nM}$ Dex and $10 \mathrm{nM} \mathrm{E}_{2}$, RNA was harvested and quantitative RT-PCR was

gene expression patterns are different in uterine leiomyomas compared to normal smooth muscle cells. SGK is induced by dexamethasone to a greater extent, while FKBP5 is induced to a lesser extent in UtLM cells. This suggests an altered responsiveness to glucocorticoids in uterine leiomyomas and compels further analysis into glucocorticoid action in UtLM cells.

\section{Biological Pathway Analysis Indicate Glucocorticoid Regulation of Cell Growth and Development}

To investigate the potential biological implications of gene regulation in uterine leiomyoma cells by glucocorticoids and estrogen, we used the Ingenuity Pathway Analysis (IPA) library to identify the most significantly regulated biological pathways under Dex, $E_{2}$, or Dex $+E_{2}$ treatment. The significantly regulated pathways under the Molecular and Cellular Function were ranked by p-value and the top five highest ranked pathways are shown (Fig. 7a). The top molecular and cellular functions identified for glucocorticoid treatment is cellular development, for estrogen treatment is cell-to-cell signaling and interaction, and for treatment with both steroids is cellular growth and proliferation. It is not surprising that important biological functions altered by $\mathrm{E}_{2}$ treatment include antigen presentation, as well as, cell-to-cell signaling. These are pathways estrogen is known to regulate in uterine leiomyomas $[25,26]$. Interestingly, cellular growth and proliferation was ranked in the top two biological functions of both Dex and Dex $+E_{2}$-treated cells, although not ranked in the top ten of $E_{2}$-treated cells. In order to examine the influence of Dex vs. $E_{2}$ on the cellular development, growth, and proliferation pathway, we overlaid values of Dex to genes in this pathway and values of $E_{2}$ (Fig. $7 b$ ). The direction of regulation was conserved for only 8 of the 35 genes in this pathway. Several genes were identified as differentially regulated by Dex and $\mathrm{E}_{2}$ in the cellular development, growth, and proliferation pathway and are indicated as shades of red (upregulation) and green (downregulation). These may represent potential targets for glucocorticoid-regulated genes that may mediate changes in cell development, growth, and proliferation.

\section{Dexamethasone Inhibits S Phase Cells in UtLM Cells}

To determine if the glucocorticoid's function in cell growth and proliferation identified by IPA can be confirmed, cell cycle analysis was performed using propidium iodide 
a

\section{DEX}

1.Cellular Development

2.Cellular Growth and Proliferation

3.Gene Expression

4.Cellular Movement

5.Cell Death

E2

1.Cell-to-Cell Signaling and Interaction

2.Antigen Presenation

3.Cellular Development

4.Cellular Movement

5.Cell Signaling

\section{Dex + E2}

1.Cellular Growth and Proliferation

2.Cellular Development

3.Cellular Movement

4.Gene Expression

5.Cell Death

Fig. 7 Genes from the dataset were associated with biological functions by Ingenuity Pathways Analysis (IPA). a Top regulated biological function for dexamethasone (Dex), estrogen $\left(E_{2}\right)$, and dexamethasone and estrogen $\left(\mathrm{Dex}+\mathrm{E}_{2}\right)$ regulated genes. b The top molecular and cellular function identified for Dex regulated genes was identified in IPA to be cellular growth and development. The color displayed in

staining and flow cytometric analysis. UtLM cells were treated with $100 \mathrm{nM}$ Dex, $10 \mathrm{nM} \mathrm{E}$, or a combination of $100 \mathrm{nM}$ Dex and $10 \mathrm{nM} \mathrm{E}$ for 24, 48, and $72 \mathrm{~h}$. As depicted in Fig. 8, treatment of UtLM cells with Dex significantly decreased the percentage of cells in $\mathrm{S}$ phase. Treatment with $\mathrm{E}_{2}$ in the presence of Dex did not significantly change the percentage of S phase cells compared to UtLM cells treated only with Dex. Other phases of cell cycle were not altered by Dex or $E_{2}$ treatment. The reduction in $\mathrm{S}$ phase cells as a result of Dex treatment occurred in a concentration dependent manner (Fig. 8b). Increasing the concentration of Dex further decreased the percentage of $\mathrm{S}$ phase cells. These results suggest that Dex inhibits DNA replication in $\mathrm{S}$ phase. Although previous studies have indicated that $\mathrm{E}_{2}$ can increase the percentage of cells in $\mathrm{S}$ phase, Dex is able to repress $\mathrm{S}$ phase cells even in the presence of $E_{2}$ [27]. Interestingly, cell death analysis by flow cytometry (data not shown) shows no difference in rates of apoptosis in Dex, $E_{2}$, or Dex $+E_{2}$-treated cells, suggesting that disruption of the cell cycle in UtLM cells does not necessarily drive cells toward apoptosis. Cell growth assays suggest that the effects of Dex on the percentage of Sphase cells may translate to differences in cell proliferation (Fig. 8c). The effect of Dex on cell cycle appears to be specific to UtLM cells. The percentage of S-phase cells in UtSMC cells treated with $100 \mathrm{nM}$ Dex, $10 \mathrm{nM} \mathrm{E}_{2}$ or a combination of $100 \mathrm{nM}$ Dex and $10 \mathrm{nM} \mathrm{E} 2$ for 24, 48, and $72 \mathrm{~h}$ do not show each shape illustrates the expression value as compared to the expression value of the same gene in the $\mathrm{E}_{2}$ regulated gene set. Each gene is classified according to function for its protein and represented by that shape based on cellular localization. The color of the shape indicates up- (red) or downregulation (green)

the same pattern of S-phase repression that UtLM cells do (data not shown).

\section{Discussion}

Glucocorticoids have several known functions in the uterus, including many that antagonize the biological actions of estrogen $[18,20]$. However, little is known about the cell type specific effects of glucocorticoids, especially in the uterus. Many studies have detailed the importance of estrogen on uterine leiomyoma growth, and the ability of glucocorticoids to antagonize the biological effects of estrogen in the uterus may translate to a similar role in leiomyoma growth. We examined these cells for the presence of the glucocorticoid receptor and through microarray analysis, identified genes expression changes with treatment by both dexamethasone and estrogen that may play a role in an antagonistic relationship. Furthermore, by identifying genes involved in the most highly regulated molecular and cellular functions through expression analysis, a potential role for glucocorticoids in uterine leiomyoma growth and proliferation was discovered.

The percentage of S-phase cells was significantly decreased by Dex treatment and co-treatment with $\mathrm{E}_{2}$ was unable to counteract this effect. Although synthetic estrogens have previously been reported to stimulate cell 
Fig. 8 Cell cycle analysis by flow cytometry. a UtLM cells were treated with Vehicle, $100 \mathrm{nM}$ of Dex, $10 \mathrm{nM}$ of $\mathrm{E}_{2}$, or $100 \mathrm{nM}$ Dex and $10 \mathrm{nM} \mathrm{E}_{2}$ for 24,48 , and $72 \mathrm{~h}$. b UtLM cells were treated with Vehicle, $10 \mathrm{nM}$ of Dex, $100 \mathrm{nM}$ of Dex, or $1000 \mathrm{nM}$ of Dex for 24, 48 , and $72 \mathrm{~h}$. c UtLM cell were plated on $10 \mathrm{~cm}$ dishes at a density of $6.4 \times 10^{4}$ cells per plate. Twenty-four hours prior to treatment, media was changed to phenol red-free MEM with charcoal dextrantreated (stripped) FBS. Cells were then treated with Vehicle, $100 \mathrm{nM}$ of Dex, $10 \mathrm{nM}$ of E2, or $100 \mathrm{nM}$ Dex and $10 \mathrm{nM} \mathrm{E}_{2}$. Each plate was counted in duplicate at $0,24,48$, and $72 \mathrm{~h}$ with a total $n$ of at least 4
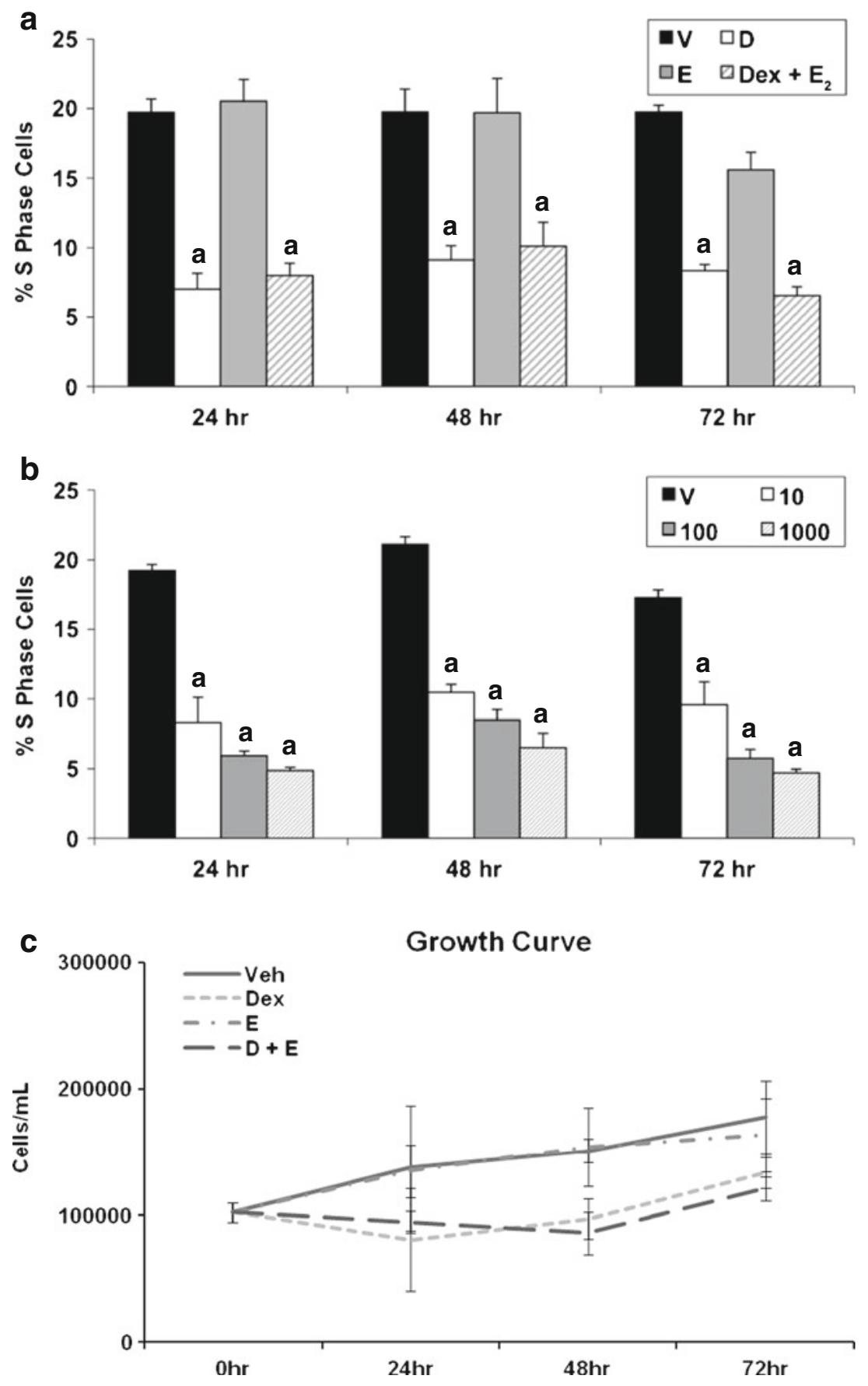

proliferation, these studies incorporated phytoestrogens with longer time points to produce these results [28]. It is interesting that Dex is able to regulate cell cycle in the presence of $E_{2}$ in this cell line since relatively few genes that were identified as antagonistically regulated by Dex and $E_{2}$. In fact, $\sim 97 \%$ of genes regulated by Dex and $E_{2}$ had similar expression patterns. These data mirror a previous study by our lab in which relatively few genes were found to be antagonistically regulated in the entire rat uterus, although Dex completely blocked the inflammatory like changes induced by $E_{2}$ [18]. However, differences exist between the two studies in the relative percentage of genes with this type of regulation identified. Where the previous study using partial genome arrays only found $1.5 \%$ of genes regulated to have antagonistic regulation, our study identified almost twice as many genes, and many are promising candidates for mediated Dex and $E_{2}$ 's effect on cell cycle progression. Expression of the $\mathrm{v}-\mathrm{myb}$ myeloblastosis viral oncogene homolog (avian)-like 1 (MYBL1), a transcription factor which promotes cell cycle progression, gene, and protein levels have been shown to be upregulated by estrogen in the UtLM cells [6]. In bovine smooth muscle cells, 
$M Y B L 1$, in conjunction with $c-M y c$, induces the progression into S-phase of the cell cycle through cell cycle-dependent expression and induction of DNA synthesis in quiescent smooth muscle cells [29]. In agreement with the cell cycle data, Dex treatment represses expression of the cell cycleinducer MYBL1 and co-treatment with Dex and $\mathrm{E}_{2}$ demonstrates a similar repression on its expression. Another antagonistically regulated candidate gene growth arrest and DNA-damage-inducible, beta $(G A D D 45 \beta)$ may also play a role in cell cycle progression, and therefore, hormoneresponsive leiomyoma growth. Members of the GADD45 family encode three highly conserved nuclear proteins that contribute to cellular homeostasis in response to genotoxic stress and DNA damage [30]. GADD45 $\beta$ interacts with several key cellular regulators, including proliferating cell nuclear antigen, cyclin $\mathrm{B} 1$, and $\mathrm{p} 21$, whereby inhibiting their activity gives $G A D D 45 \beta$ its function in negative growth control [31]. GADD $45 \beta$ has also been implicated in several human cancers and $G A D D 45 \beta-/-$ mice increased susceptibility to chemical carcinogenesis and accelerated melanoma growth [32]. Interestingly, expression of $G A D D 45 \beta$ is repressed by $\mathrm{E}_{2}$ and induced by Dex treatment in the UtLM cell line. In cells treated with both Dex and $\mathrm{E}_{2}$, $G A D D 45 \beta$ is also induced, showing a reversal of the $\mathrm{E}_{2}$ effect by Dex. It is also possible that genes critical to the pathogenesis of leiomyomas that are antagonistically regulated by Dex and $E_{2}$ have not been identified due to the finite nature of the current microarray platform and investigating a single time point. Progress in sequencing-based expression analysis technologies will provide advances in the robustness and resolution of genomic studies.

Another possibility may be that genes important for regulating key cellular processes in the uterine leiomyomas do not necessarily need to be antagonistically regulated to be differentially regulated. For instance, 12 genes were identified as antagonistically regulated by Dex and $\mathrm{E}_{2}$, but 185 genes were identified that have at least a 2-fold difference in expression level when comparing Dex and $\mathrm{E}_{2}$ treatment. For many of these genes, Dex downregulates their expression to some extent but $\mathrm{E}_{2}$ further increases this repression. An example of expression regulation is progesterone receptor domain containing protein 14 (PRDM14), a transcriptional regulator important for pluripotency and epigenetic reprogramming, is downregulated by Dex about 8fold but close to 13-fold with $\mathrm{E}_{2}$ treatment [33]. Several other genes involved in the inflammatory pathway were also identified by examining large changes in expression with Dex and $\mathrm{E}_{2}$. Cluster of differentiation $48(C D 48)$ is a critical effector molecule in the immune response with many biological functions ascribed to it including, cell adhesion, pathogen recognition, cellular activation, and cytokine regulation [34]. This cytokine is downregulated 11-fold by Dex but 18 -fold by $E_{2}$ in UtLM cells, which may suggest part of the mechanism by which $\mathrm{E}_{2}$ is able to induce leiomyoma development in an immune-competent individual. Another immune regulator found with a similar pattern of complementary repression by $\mathrm{E}_{2}$ is chemokine (C-C motif) ligand 15 (CCL15), a small cytokine that acts as a chemotactic for neutrophils, monocytes, and lymphocytes by binding cell surface chemokine receptors [35]. CCL15 is downregulated by Dex but further repressed by $\mathrm{E}_{2}(6.5 \mathrm{v}$. 13.8 -fold, respectively). These and many of 185 genes identified as differentially regulated by Dex and $\mathrm{E}_{2}$ are candidates for mediating the pathogenesis of uterine leiomyomas mediated by $\mathrm{E}_{2}$ and potentially glucocorticoids.

We previously reported that glucocorticoids can block the biological effects of estrogen in the uterus. This study provides the first evidence that this antagonism acts not only in a global manner but also in a cell-specific manner in the uterus, specifically a uterine tumor in which many questions remain regarding the regulation of its endocrinology [18]. The clinical implications of the current findings are significant and have the potential to improve current strategies in the development of treatment for uterine leiomyomas. First, these findings suggest interplay of estrogen and glucocorticoids regulates gene expression in a human uterine leiomyoma cell line. While a relative small percentage of genes are antagonistically regulated, in co-regulated genes, treatment with glucocorticoids is largely able to modulate estrogen's effect on gene expression. Furthermore, glucocorticoid treatment can repress the amount of cells undergoing DNA replication in S-phase of the cell cycle, and candidate genes have been identified that may mediate this cell cycle check point. Promoter analysis suggests that this could occur through either a direct mediation of response element binding by estrogen or glucocorticoids or indirectly through modulation by NFKB signaling.

Samples from patients reveal hGR expression in both normal and leiomyoma tissue and may represent a target for therapies in vivo. Inclusion of glucocorticoids as a therapy for leiomyoma growth and development will depend on a better understanding of the molecular process by which glucocorticoids can antagonize estrogen's genomic and biological functions and whether these findings can translate to an intact uterine environment.

Acknowledgments This research was supported by the Intramural Research Program of the NIH National Institute of Environmental Health Sciences.

\section{References}

1. Buttram VC Jr, Reiter RC (1981) Uterine leiomyomata: etiology, symptomatology, and management. Fertil Steril 36(4):433-445

2. Okolo S (2008) Incidence, aetiology and epidemiology of uterine fibroids. Best Pract Res Clin Obstet Gynaecol 22(4):571-588 
3. Miller NF, Ludovici PP (1955) On the origin and development of uterine fibroids. Am J Obstet Gynecol 70(4):720-740

4. Stewart EA (2001) Uterine Fibroids. Lancet 357(9252):293-298

5. Hunter DS et al (2000) Influence of exogenous estrogen receptor ligands on uterine leiomyoma: evidence from an in vitro/in vivo animal model for uterine fibroids. Environ Health Perspect 108 (Suppl 5):829-834

6. Swartz CD et al (2005) Estrogen-induced changes in IGF-I, Myb family and MAP kinase pathway genes in human uterine leiomyoma and normal uterine smooth muscle cell lines. Mol Hum Reprod 11(6):441-450

7. Cook JD, Walker CL (2004) Treatment strategies for uterine leiomyoma: the role of hormonal modulation. Semin Reprod Med 22 (2): $105-111$

8. Sener AB et al (1996) The effects of hormone replacement therapy on uterine fibroids in postmenopausal women. Fertil Steril 65 (2):354-357

9. Brandon DD et al (1995) Estrogen receptor gene expression in human uterine leiomyomata. J Clin Endocrinol Metab 80(6):18761881

10. Pollow K et al (1978) Estrogen and progesterone binding proteins in normal human myometrium and leiomyoma tissue. J Clin Chem Clin Biochem 16(9):503-511

11. Walker CL et al (2000) Preclinical evidence for therapeutic efficacy of selective estrogen receptor modulators for uterine leiomyoma. J Soc Gynecol Investig 7(4):249-256

12. Zanchi NE et al (2010) Glucocorticoids: extensive physiological actions modulated through multiple mechanisms of gene regulation. J Cell Physiol 224(2):311-315

13. Whirledge S, Cidlowski JA (2010) Glucocorticoids, stress, and fertility. Minerva Endocrinol 35(2):109-125

14. Nicolaides NC et al (2010) The human glucocorticoid receptor: molecular basis of biologic function. Steroids 75(1):1-12

15. Edwards CR et al (1996) 11 beta-Hydroxysteroid dehydrogenases: key enzymes in determining tissue-specific glucocorticoid effects. Steroids 61(4):263-269

16. Michael AE, Thurston LM, Rae MT (2003) Glucocorticoid metabolism and reproduction: a tale of two enzymes. Reproduction 126(4):425-441

17. Bever AT, Hisaw FL, Velardo JT (1956) Inhibitory action of desoxycorticosterone acetate, cortisone acetate, and testosterone on uterine growth induced by estradiol-17beta. Endocrinology 59 (2): $165-169$

18. Rhen $\mathrm{T}$ et al (2003) Dexamethasone blocks the rapid biological effects of 17 beta-estradiol in the rat uterus without antagonizing its global genomic actions. Faseb J 17(13):1849-1870

19. Bitman J, Cecil HC (1967) Differential inhibition by cortisol of estrogen-stimulated uterine responses. Endocrinology 80(3):423429
20. Rhen T, Cidlowski JA (2006) Estrogens and glucocorticoids have opposing effects on the amount and latent activity of complement proteins in the rat uterus. Biol Reprod 74(2):265-274

21. Carney SA et al (2002) Immortalization of human uterine leiomyoma and myometrial cell lines after induction of telomerase activity: molecular and phenotypic characteristics. Lab Invest 82 (6):719-728

22. Cidlowski JA et al (1990) Novel antipeptide antibodies to the human glucocorticoid receptor: recognition of multiple receptor forms in vitro and distinct localization of cytoplasmic and nuclear receptors. Mol Endocrinol 4(10):1427-1437

23. Ballard PL, Mason RJ, Douglas WH (1978) Glucocorticoid binding by isolated lung cells. Endocrinology 102(5):1570-1575

24. Saceda M et al (1988) Regulation of the estrogen receptor in MCF7 cells by estradiol. Mol Endocrinol 2(12):1157-1162

25. Kayisli UA, Guzeloglu-Kayisli O, Arici A (2004) Endocrineimmune interactions in human endometrium. Ann N Y Acad Sci 1034:50-63

26. Maruo T et al (2004) Sex steroidal regulation of uterine leiomyoma growth and apoptosis. Hum Reprod Update 10(3):207-220

27. Gao $X$ et al. An endocrine-disrupting chemical, fenvalerate, induces cell cycle progression and collagen type I expression in human uterine leiomyoma and myometrial cells. Toxicol Lett 196(3):133-141

28. Moore AB et al (2007) Stimulatory and inhibitory effects of genistein on human uterine leiomyoma cell proliferation are influenced by the concentration. Hum Reprod 22(10):2623-2631

29. Marhamati DJ et al (1997) A-myb is expressed in bovine vascular smooth muscle cells during the late G1-to-S phase transition and cooperates with c-myc to mediate progression to S phase. Mol Cell Biol 17(5):2448-2457

30. Liebermann DA, Hoffman B (2007) Gadd45 in the response of hematopoietic cells to genotoxic stress. Blood Cells Mol Dis 39 (3):329-335

31. Vairapandi $M$ et al (2002) GADD45b and GADD45g are cdc2/ cyclinB1 kinase inhibitors with a role in $\mathrm{S}$ and $\mathrm{G} 2 / \mathrm{M}$ cell cycle checkpoints induced by genotoxic stress. J Cell Physiol 192 (3):327-338

32. Ju S et al (2009) Gadd45b and Gadd45g are important for antitumor immune responses. Eur J Immunol 39(11):3010-3018

33. Yamaji $\mathrm{M}$ et al (2008) Critical function of Prdm14 for the establishment of the germ cell lineage in mice. Nat Genet 40(8):10161022

34. Munitz A, Bachelet I, Levi-Schaffer F (2007) CD48 as a novel target in asthma therapy. Recent Pat Inflamm Allergy Drug Discov 1(1):9-12

35. Youn BS et al (1997) Molecular cloning of leukotactin-1: a novel human beta-chemokine, a chemoattractant for neutrophils, monocytes, and lymphocytes, and a potent agonist at CC chemokine receptors 1 and 3. J Immunol 159(11):5201-5205 